\title{
Editorial
}

\section{Neuropediatrics News 2015}

\author{
Barbara Plecko ${ }^{1}$ Eugen Boltshauser ${ }^{2}$ Bernd A. Neubauer ${ }^{3}$ \\ ${ }^{1}$ Department of Neuropediatrics, University of Zurich, \\ Zurich, Switzerland \\ 2 Department of Neuropediatrics, Prof. Emeritus, University of Zurich, \\ Zurich, Switzerland \\ ${ }^{3}$ Department of Neuropediatrics, University of Giessen, \\ Giessen, Germany \\ Neuropediatrics 2015;46:1-2.
}

\section{Dear Readers of Neuropediatrics}

Another new year has just begun and we want to take the occasion to wish you all a happy, healthy, and fruitful year of 2015.

As you may be aware, Neuropediatrics is the official journal of the „Gesellschaft für Neuropädiatrie“ (GNP). In this editorial, we want to update you on recent changes in our board, following the election at the "Neurowoche“ in Munich in September 2014. Barbara Plecko (Zurich) and Bernd Neubauer (Giessen) have stepped down as president and treasurer of the society and so have Maja Steinlin (Bern) and Kevin Rostasy (Datteln, formerly Innsbruck)-the Swiss and Austrian representatives. Ulrike Schara (Essen) has been elected as the new president and Matthias Kieslich (Frankfurt) has been reelected as vice president. Thomas Lücke (Bochum) will take the responsibility as the new treasurer, Andreas Sprinz (Havixbeck) as the new secretary, and Folkert Fehr (Heidelberg) will represent the Child Neurologists working in private practice. Andrea Klein (Zurich) and Manuela Baumgartner (Linz) have been elected as the new representatives for Switzerland and Austria, respectively. GNP is a prospering society with now 903 members, mainly deriving from the German-speaking, European countries. Being a scientific society and a nonprofit organization, rising taxes and running costs necessitated a cut of expenses during the past year of 2014. Beyond trimming the society's infrastructure, we felt that this was the right time to reevaluate an online-only subscription for the members of our society. Thieme, as our longstanding partner, has offered a new contract with a package of online-only subscription for all members and the option of print issues on an individual level at an additional rate of $€ 30$. Technical details have been communicated to all GNP members early in 2015. The new contract allowed us to leave the membership fees of
$€ 130$ unchanged, saving about €80per member. The board took this decision in the best interest of our members as this will allow coverage of the running costs of our society, independently of the varying surplus from our yearly conferences.

Neuropediatrics, as the official journal of our society, is dedicated to publish articles that focus on neurobiology, neurology, and neurogenetics of childhood disorders. In the year of 2014, we have been able to publish a total of 30 original articles, 5 invited review articles, 5 editorials, and 25 short communications in 6 issues, covering 410 pages. The three Editors-in-Chief, supported by a group of associated editors as well as by an editorial board, aim at short turnaround times and early online access of accepted articles. On this occasion, we also want to thank the many reviewers, who by their expert opinion, contribute to the high quality of our journal. The past year has brought the introduction of supplementary online material as well as patient videos as an instantly appreciated novelty. In line with many other journals, Neuropediatrics had to become more restrictive in accepting single case reports. As the editors are convinced that descriptions of rare clinical entities still deserve publication, this section will be preserved, but submissions of case reports need to present exceptional observations of broader importance. During the Neurowoche in Munich, the editorial team felt that many abstract presentations of the yearly GNP conference were of high quality and would be of interest to a greater circle of child neurologists. Thus we want to encourage active participants of the GNP conference to submit their work for publication in Neuropediatrics. Our society has a longstanding relation to the Neuropediatrics journal and it is due to all of us to fill this journal with valuable content and to sustain its high quality in the near and far future.
Address for correspondence Prof. Barbara Plecko, MD, University Children's Hospital, Steinwiesstrasse 75, $\mathrm{CH}-8032$ Zurich, Switzerland (e-mail: Barbara.Plecko@kispi. uzh.ch).
(C) 2015 Georg Thieme Verlag KG Stuttgart · New York
DOI http://dx.doi.org/ $10.1055 / \mathrm{s}-0035-1544186$. ISSN 0174-304X. 


\begin{tabular}{|c|c|c|}
\hline \multicolumn{3}{|c|}{ Thank You, Reviewers! } \\
\hline Till Acker & Raoul Hennekam & Kenichi Oishi \\
\hline Filippo Arrigoni & Johann Holthausen & Akihisa Okumura \\
\hline Stephane Auvin & David Holzmann & Heather Olson \\
\hline Robert Avery & Yuji Inaba & Hitoshi Osaka \\
\hline James Barkovich & Bale James & Robert Ouvrier \\
\hline Thomas Bast & Andreas Jansen & Jessica Panzer \\
\hline Christoph Berger & Andreas Jödicke & Zoltan Patay \\
\hline Günther Bernert & Matthias Kieslich & Aurelia Peraud \\
\hline Faith Bischof & Janbernd Kirschner & Heike Philippi \\
\hline Astrid Blaschek & Katrin Klebermass-Schrehof & Barbara Plecko \\
\hline Eugen Boltshauser & Joerg Klepper & Daniela Pohl \\
\hline Ingo Borggraefe & Gerhard Kluger & Andrea Poretti \\
\hline Knut Brockmann & Stefan Koelker & Susana Quijano-Roy \\
\hline Marco Carotenuto & Hirohumi Komaki & Georgia Ramantani \\
\hline Caterina Cerminara & Uri Kramer & Markus Rauchenzauner \\
\hline Chao Cho-Ming & Kathrin Krohn & James Reese \\
\hline Alexander Claviez & Jonathan Kurz & Andrea Rossi \\
\hline Russell C. Dale & Mirjam Landgraf & Kevin Rostásy \\
\hline Joseph M. Dooley & Suvi liimatainen & Sahar Saleem \\
\hline Olivier Dulac & Doris Lin & Gebhard Sammer \\
\hline Friedrich Ebinger & Marios Loukas & Harvey Sarnat \\
\hline Harald Erhardt & Rolf Maier & Ulrike Schara \\
\hline Evans Gareth & Volker Mall & Deborah Sival \\
\hline Dirk Faas & Yuji Masuda & Nicola Specchio \\
\hline Martha Feucht & Victor Mautner & Maja Steinlin \\
\hline Dirk Fischer & Johannes Mayr & Volker Straub \\
\hline Bernhard Frey & Jennifer McGuire & Marc Tardieu \\
\hline Carlo Fusco & Friedrike Moeller & Regina Trollmann \\
\hline Sabina Gallati & Maria Mosquera & Andreas van Baalen \\
\hline Svetlana Gataullina & Wolfgang Mueller-Felber & Adeline Vanderver \\
\hline Lucia Gerstl & Ulrich Müller & Federico Vigevano \\
\hline Kevin Gordon & Kazuhiro Muramatsu & Axel Weber \\
\hline Michael A. Grotzer & Rima Nabbout & Marko Wilke \\
\hline Claudine Gysin & David Nadal & Michel Willemsen \\
\hline Johannes Haeberle & Toshisaburo Nagai & Jan-Maarten Wit \\
\hline Martin Häusler & Nardo Nardocci & Claus Wittekindt \\
\hline Martin Haeusler & Sona Narual & Gabriele Wohlrab \\
\hline Andreas Hahn & Giancarlo Natalucci & Nicole Wolf \\
\hline Hans Hartmann & Jun Natsume & Courtney Wusthoff \\
\hline Florian Heinen & Bernd A. Neubauer & Werner Zenz \\
\hline Ingo Helbig & David Neubauer & jill Zwicker \\
\hline Christoph Helmstaedter & Erik Niks & \\
\hline
\end{tabular}

